\title{
¿Vigilad el cielo (y la tierra)! \\ Cosas de este y del otro mundo ${ }^{1}$
}

\section{Watch the Skies (and the Earth)! Things From In and Out Of This World}

\author{
ANTON GIULIO MANCINO \\ Università degli Studi di Macerata (Italia) \\ antongiulio@virgilio.it \\ ORCID ID: 0000-0001-9305-0039
}

\begin{abstract}
Resumen: ¿Cuáles y cuántas «Cosas» han atestado la literatura y el cine de ciencia ficción, comenzando por el relato «Who Goes There?» de John W. Campbell y la primera película, El enigma de otro mundo, basada en este mismo, a cargo de Christian Nyby y Howard Hawks, y después versionada por John Carpenter con el simple título de La Cosa? ¿Y cómo se llega al cuadro histórico-político de la Italia de los años setenta a través del filtro de la ciencia ficción? ¿Por qué, por ejemplo, la Italia marcada por el poder mafioso («Cosa Nostra») y por el terrorismo se convierte en el espacio funcional privilegiado del «paradigma de la cosa»? A desentrañar el fantasma imperioso de estas oscuras, a veces concomitantes «Cosas» italianas, duraderas, insidiosas, se encomienda el presente artículo.
\end{abstract}

Palabras clave: adaptación fílmica; John W. Campbell; John Carpenter; «Who Goes There?»; La Cosa.

\begin{abstract}
What and how many are the «Things» that have crowded science fiction literature and cinema, beginning with the story «Who goes there?», by John W. Campbell, and the first film, The Thing from Another World, extracted from this book by Christian Nyby and Howard Hawks and, after that, the remake by John Carpenter with the simple title The Thing? And how do we get to the historical-political chart of Italy in the 70 s through the filter of science fiction? Why, for example, the Italy marked by the mafia power ( «Cosa Nostra») and terrorism becomes the privileged functional space of the «thing paradigm»? This paper is entrusted unravel the imperious ghost of these dark, sometimes concomitant, enduring, insidious, Italian «Things».
\end{abstract}

Keywords: film adaptation; John W. Campbell; John Carpenter; «Who Goes There?»; The Thing.

\footnotetext{
${ }^{1}$ La traducción del artículo, redactado originalmente en italiano, ha sido efectuada por Pedro J. Plaza González (Universidad de Málaga) y Lorenzo Cittadini (Università Ca' Foscari Venezia).
} 


\section{Anton Giulio Mancino}

No, by the grace of God, who evidently does hear very well, even down here, and the margin of half an hour, we keep our world, and the planets of the system too. Anti-gravity, you know, and atomic power. Because They came from another sun, a star beyond the stars. They came from a world with a bluer sun.

(John W. Campbell, Who Goes There?)

Yo no tenía ninguna esperanza, y sin embargo vivía de esperanzas; desde que ella había desaparecido, no me quedaba otra cosa. No sabía qué descubrimientos, qué burlas, qué torturas me aguardaban aún. No sabía nada, y me empecinaba en creer que el tiempo de los milagros crueles aún no había terminado.

(Stanislav Lem, Solaris)

No es, desde luego, tarea fácil dibujar a la «Cosa» basándose en las descripciones verbales contenidas en el relato original de Don A. Stuart, pseudónimo de John Wood Campbell, «Who Goes There?», publicado en el número de agosto de 1938 de la revista Astounding. El problema de fondo de tratar de representar a la «Cosa» es el mismo que el del inefable «enorme insecto» en el que «se encontró convertido» de repente Gregor Samsa, sin tan siquiera la posibilidad de verse correctamente. Si de La metamorfosis de Franz Kafka ha sido, por tanto, difícil sacar un «insecto desde el agujero», imaginen con la «Cosa» de Stuart/Campbell. No obstante, si de La metamorfosis (Die Verwandlung, 1915) no existen versiones cinematográficas de nivel, de «Who Goes There?» sí que las hay. Dos: El enigma de otro mundo (The Thing from Another World, 1951) de Christian Nyby y Howard Hawks -no reconocido en los créditos-, y más tarde el remake de John Carpenter, La Cosa (The Thing, 1982); e incluso una tercera versión, añadiendo la precuela homónima del filme de Carpenter, La Cosa (The Thing, 2011), dirigido por Matthijs van Heijningen Jr.; y eso sin contar las innumerables derivaciones o contaminaciones no oficiales.

A «reconstruirla» gráficamente, porque en la película de Nyby y Hawks la «Cosa» era demasiado antropomórfica, probó el diseñador americano George Barr en 1961. Esta imagen de la «Cosa» tiene tres ojos, brazos como tentáculos, pies armados de uñas fuera de lo común, cabellos comparables - por usar las palabras de Campbell— a un «repugnante nido de gusanos temblorosos». Carpenter y los creadores de los efectos especiales mecánicos de La Cosa de 1982 debieron de tener presente el diseño de Barr o, en cualquier caso, debieron de haber leído y releído el relato original, adentrándose más allá del umbral de una obra que simplemente se deja ver. Más allá de la propia película, muy admirada por Nyby y, sobre todo, por 


\section{¡Vigilad el cielo (y la tierra)!}

Hawks. El diseño es retomado por la revista española Nueva Dimensión, número 6 de noviembre-diciembre de 1968. Y 1968 es un año fundamental para el nacimiento del new horror americano, ya filtrado por sugestiones de la ciencia ficción, con La noche de los muertos vivientes (Night of the Living Dead, 1968) de George A. Romero, inspirada, por otra parte, en una célebre novela de ciencia ficción de Richard Matheson, Soy leyenda (I Am Legend, 1954), llevada a la gran pantalla oficialmente al menos en tres ocasiones: $E 1$ último hombre sobre la tierra (The Last Man on Earth, 1964), de Sidney Salkow y Ubaldo Ragona; El último hombre vivo (The Omega Man, 1971), de Boris Sagal; y Soy leyenda (I Am Legend, 2007), de Francis Lawrence.

La proliferación de todas estas «Cosas» nos lleva a reflexionar sobre la naturaleza fundamental de la «Cosa» original y de sus derivaciones, metamorfosis en todos los sentidos o implicaciones estratificadas y cruzadas (Arona, 1983). Es evidente que la «Cosa» es un concepto muy fértil cinematográficamente hablando, especialmente a través de la ciencia ficción, cuando intercepta el terror o cuando el terror intercepta la ciencia ficción. Un concepto, aparte de los géneros de referencia más acreditados, ya ejemplificado en clave estrictamente cinematográfica por Lacan mediante el recurso de la

figura $[\ldots]$ del terrible mudo de los cuatro hermanos Marx, Harpo. ¿Hay quizás algo que pueda poner una cuestión en un modo más presente, más urgente, más involucrador, más molesto, más nauseabundo, más hecho para lanzar al abismo y a la nada todo aquello que sucede en su presencia, que esa cara marcada por una sonrisa de la cual no se sabe si es aquella de la más extrema perversión o aquella de la estupidez más absoluta, la cara de Harpo Marx? Este mudo basta solo para resistir el clima de cuestionamiento y aniquilación radical, el cual constituye la trama de la farsa formidable de los Marx y del ininterrumpido juego de bromas que da todo el valor a su número (2008: 65).

Žižek, retomando debidamente el ejemplo lacaniano, lo desarrolla en sentido cinematográfico. Y añade: «Esta incertidumbre, o más bien inconmensurabilidad absoluta, lo convierte en una Cosa monstruosa, una Cosa de Otro aquí, no un compañero intersubjetivo, sino un compañero completamente no humano» (2011: 7). El trasvase de Harpo/Cosa a La Cosa, preferiblemente en la versión de Carpenter, dada la predilección del filósofo esloveno por el autor de Están vivos (They Live, 1988) -el filme con el cual eligió inaugurar el documental Guía ideológica para pervertidos (The Pervert's Guide to Ideology, 2012), de Sophie Fiennes-, es, por tanto, breve y obligado. Por un lado, pues, está Carpenter, que intenta resolver el problema figurativo creando una progresión de formas mixtas que conducen gradualmente a la acumulación, y de ahí a la abstracción. Y lo hace mostrando desde el principio el shock visual de un inocuo perro que se abre y se pela como un plátano, generando otras formas animales dotadas de piernas-tentáculos y de todo lo demás. Luego, sabiendo que ya no puede 
obtener el mismo resultado de la primera vez, se vuelca hacia la invención de los dibujos animados, por lo que muestra un vientre humano que abre la boca con dientes enormes y una cabeza humana que saca las patas y se convierte en una especie de araña gigante con ojos de caracol. La tercera vez ya no se centra en el «monstruo», sino en su porción mínima, o sea, la sangre que salpica las calles sin que haya escapatoria. Aplica, prácticamente, lo que en literatura se conoce como la figura retórica de la sinécdoque, jugando, por lo tanto, con la parte que hace referencia al todo. También el shock está asegurado, en esta ocasión por vías transversales. Al final, puede permitirse mostrar una «Cosa» general, sumando todas las «cosas» parciales ya vistas. Y hasta aquí Carpenter. Žižek construye casi enteramente en su libre excurso cinematográfico que trae de vuelta a la «Cosa», y por consiguiente a La Cosa carpenteriana, la aplicación del paradigma de la «Cosa» sobre la filmografía de Andrej Tarkovskij, en particular sobre dos películas de ciencia ficción: Solaris (Солярис, 1972) у consecuentemente Stalker (Сталкер, 1979), basadas respectivamente en la novela homónima de Stanislaw Lem de 1961 y de la novela Picnic extraterrestre (Пикник на обочине, 1972) de los hermanos Arkadij y Boris Strugackij, publicada en 1972. Ahora, en la primera El enigma de otro mundo, es fácil imaginar el ser inmundo que pone patas arriba la base militar en el Antártico. No solo el Alienígena, que, desde la página escrita en 1938, tal vez haciendo referencia al fascismo nazi que estaba a punto de desatar la Segunda Guerra Mundial, pasa en 1951 a la amenaza comunista o a la Guerra Fría. La película de Hawks y Nyby — y la inversión del orden asignado a los dos apellidos no es casual — invita al final a «vigilar el cielo», pero también un poco la Tierra, desde el momento en que la verdadera amenaza para el equipo masculino y para un modelo de sociedad inmaduro y violento de matriz machista, como siempre en las películas de Hawks, es más bien la mujer. En el filme de Carpenter, en los inicios de los años ochenta, en un clima recrudecido por la Guerra Fría, no es, sin embargo, el peligro comunista el problema. Carpenter, mostrando plenamente la «Cosa», sobre las líneas literarias de Campbell, se atreve a ir más allá y advierte al hombre del hombre, a la humanidad de sí misma, de sus monstruosidades internas, de sus propias entrañas. A Carpenter la forma ya no le interesa, porque sabe que asustar, desde 1982 hasta hoy, es la ausencia de forma, de dimensiones y de localización del objeto del miedo. Ayer, los platillos volantes, los marcianos o los comunistas, que provenían del otro lado y de este mundo; hoy, los virus que nacen y proliferan únicamente sobre este mundo, capilares e invisibles como las gotas de sangre que se arrastran hacia fuera y pueden difundirse por cualquier parte. Carpenter, en suma, al exhibir a simple vista a la «Cosa», le devuelve la invisibilidad absoluta e inminente.

Conviene ahora, no obstante, tratar de dar un paso atrás, retornando a los contenidos políticos de la «Cosa», contenidos que en Italia encuentran una aplicación específica. Y, de hecho, en Italia la «Cosa» en particular y la ciencia ficción en general asumen una fuerte y declarada connotación 


\section{¡Vigilad el cielo (y la tierra)!}

política. Si se mira a un cierto modelo de cine italiano, que concretamente en los años setenta interactúa con cuestiones de carácter políticocircunstancial de inmensa gravedad, se descubre cómo la «Cosa» sintomática de la ciencia ficción y de la política, sin soluciones de continuidad, se halla en equilibrio entre la «perversidad más extrema» y la «estupidez más completa». De una parte, Harpo Marx, expresión consumada del singular y cinematográfico «cuestionamiento», y de la «aniquilación radical» (Lacan, 2008: 65); de otra parte, la posibilidad concreta de transferir tales características tocantes a la muy italiana faceta de la profunda incertidumbre cognitiva y a la crisis irremediable del valor civil, histórico y judicial de toda una época. Operación que tiene sus ventajas prácticas y contribuye, a menudo, «a explicar la razón de tantas Cosas», como diría Niccolò Farra, el protagonista de Identificazione di una donna (1982), de Michelangelo Antonioni. Niccolò es, casualmente, un director de cine que lidia con «Cosas» y con acontecimientos no del todo privados, que se entrelazan con los de la pareja de exponentes de las Brigadas Rojas que en aquel entonces apenas habían sido arrestados, después del secuestro y del asesinato del presidente del partido Democracia Cristiana (DC), el honorable Aldo Moro: se trata de los «disociados» Adriana Faranda y Valerio Morucci. Pero hay también otros objetos y sucesos no menos extraños o indescifrables que involucran en primera persona a Niccolò Farra como personaje y a Michelangelo Antonioni como intelectual. El director de la película, en el filme, quizá no capta el vínculo existente entre estas «Cosas», o quizá lo capta demasiado, mezclando el ámbito privado con la pantalla. Él está pensando en la enésima «historia de amor», como le reprocha su amigo guionista. Pese a ello, al final renuncia a «su» historia de amor cinematográfica porque en su vida privada fracasa en el amor dos veces, tres si se cuenta acaso el matrimonio a sus espaldas. Llegado a este punto, no le queda más que dedicarse a una película de ciencia ficción; sin embargo, no se dice que haya descartado por completo el proyecto de una historia donde la única certeza parecía ser «que el personaje femenino es una mujer» o, en realidad, «un sentimiento que tiene formas femeninas». Desde la «CosaMujer», guiándose por el paradigma hawksiano, se ha desplazado, aunque poco, a la «Cosa-Sol», la cual puede tratar de aproximarse únicamente a un vehículo de este tipo: «Mi astronave», explica Niccolò a su sobrino, «es un asteroide capturado en el espacio y transformado en astronave». En la práctica, otra «Cosa», el Hombre, que apunta hacia la «Cosa» por excelencia, la Mujer, entidad desconocida, escurridiza, inaccesible y que irradia luz y calor. Como el Sol. «Entonces», pregunta el niño, «ipor qué acercarse al Sol?». Respuesta del adulto: «Para estudiarlo. El día en que el hombre logre comprender cómo está distribuida la materia dentro del sol, y su dinámica, tal vez entienda cómo está hecho todo el universo... y la 
razón de muchas cosas» ${ }^{2}$. Fundido cruzado. En el guion transcrito, se usa la c minúscula (Antonioni, 1983: 155). Nosotros preferimos la mayúscula: «Cosas». Tantas otras oscuras «Cosas». Todas conectadas, concomitantes, contingentes.

He aquí el recurso de la ciencia ficción, el principal género en el que la «Cosa» encuentra desde siempre un amplio espacio mediático como un «misterioso objeto alienígena no muerto que cae del universo, un objeto no humano, pero, sin embargo, viviente e incluso capaz de tener, a menudo, su propia voluntad maligna» (Antonioni, 1983: 135). Resulta extremadamente valioso en un determinado contexto, fílmico y profílmico a un tiempo, porque vehicula con frecuencia el discurso de la «Cosa» y con él el de la ciencia ficción, el cual en el ámbito italiano no se presenta solo bajo la especie metafórica, sino que, por el contrario, se presta muy bien a hacerse cargo de indescifrables, oscuras «Cosas» que transitan desde los años setenta a los primeros años ochenta, esto es, cuando Antonioni decide dedicarse a su parábola del amor y de la ciencia ficción. Hasta que, a las puertas de los noventa, con el conocimiento apropiado de la causa no solo cinéfila, es a Nanni Moretti a quien le corresponde actuar sin miramientos para legitimar «el paradigma de la Cosa» al pie de la letra. Moretti, de hecho, explicita todo al titular su documental de 1990 como la película de Nyby/Hawks o, más probablemente, la relectura no eufemística de Carpenter: La cosa, un documental sobre el nuevo sujeto político que se está preparando para copiar, remodelar y reemplazar al «viejo» Partido Comunista Italiano (PCI). En resumen, Moretti sabe que se ha aventurado - con la complicidad del título La cosa - en la exploración de la génesis de una criatura relativamente «alienígena», ajena a la tradición y a la ortodoxia comunista, destinada a surgir de un debate sobre los límites de la autoconciencia colectiva, en la cual tanto la cúspide como la base de los militantes afronta/exorciza una crisis histórica. ¿Qué mejor título que aquel del remake de autor de un filme de autor y de género, un género preciso, para dar cuenta del éxito de una complicada y combatida metamorfosis, como si estuviese lidiando con un ser venido de otro planeta? ¿Qué mejor cita fílmica para testificar en tiempo real el estado de un objeto no identificado, aún sin un nombre, una abreviatura, un reconocimiento compartido y, por lo tanto, vagamente de ciencia ficción? ¿Qué mejor atributo para ese PCI a punto de convertirse en otra Cosa, más actual y prescindible en la escena política nacional? Dicho de otro modo, la llamada

\footnotetext{
${ }^{2}$ En el tratamiento original, escrito en forma de novela, es el sobrino quien sugiere a Niccolò la idea de una película de ciencia ficción, que produce de inmediato un resultado: «Cuando regresa a casa, el sol está cayendo. El horizonte es plano frente a sus ventanas. Niccolò saca el telescopio y lo lleva hacia el sol. Una vez más lo que ve es fascinante. Un pedazo de sol de color naranja violento, con pocas manchas negras, y los contornos que fluctúan como ondas incandescentes: las llamas solares. Le parece ver algo que se mueve, en medio de las llamas. Es su imaginación que trabaja. Sigue trabajando hasta que el sol no se va bajo el horizonte» (Antonioni, 1983: 36).
} 


\section{¡Vigilad el cielo (y la tierra)!}

de Moretti a la enésima «Cosa» suena, asimismo, oportuna, además de ser filológicamente correcta, ya que lo que está en juego es la nueva versión del PCI.

Si no fuera así, no se lograría ni siquiera comprender la decisión previa de Damiano Damiani de adjudicar, a mitad de los años setenta, al protagonista de ¿Por qué se asesina a un magistrado? (Perché si uccide un magistrato, 1975) un apellido emblemático: «Solaris». A través de su Solaris, Damiani intenta afrontar bajo la forma de un examen de conciencia personal el excelente asesinato del fiscal de Palermo, Pietro Scaglione. Por este motivo, recurre al título y a la idea del ya citado Solaris de Lem. Atención a las fechas: la novela se publica en 1961, mientras Tarkovskij la lleva a la gran pantalla once años después, apenas tres años antes de ¿Por qué se asesina a un magistrado?. La denuncia, la investigación y la contrainvestigación de la película de Damiani sobre un delito atribuido a la mafia lo induce a optar por el modelo de la «Cosa». En síntesis, una «Cosa» tira de la otra, de la «Cosa Nostra» a la «Cosa» de Lem y a la consecuente de Tarkovskij. Según Žižek, «este Cerebro gigante, esta otra Cosa», el planeta «que implica un cortocircuito psicótico»; «una oscura máquina descentralizada que "lee" los [...] sueños más íntimos [del hombre] y se los devuelve como síntomas, es decir, le devuelve el mensaje en su forma verdadera, que, no obstante, el sujeto no está preparado para reconocer»; «un mecanismo que materializa directamente nuestras fantasías inconfesadas (2011: 20, 26 y 30).

Y así,

la comunicación con la Cosa-Solaris fracasa no porque Solaris sea demasiado alienígena, el signo de un intelecto infinitamente superior a nuestras limitadas capacidades, el cual lleva a cabo con nosotros juegos perversos cuyo sentido permanecerá por siempre más allá de nuestra comprensión, sino porque nos lleva demasiado cerca de lo que, dentro de nosotros, debe mantener una cierta distancia si queremos preservar la coherencia de nuestro universo simbólico (2011: 34-35).

La praxis contradeductiva de ¿Por qué se asesina a un magistrado?, encomendada a otro director principal, que precede al director Niccolò/Antonioni de Identificazione di una donna, pasa a través del reclamo no solo onomástico del mayor ejemplar de «con-ciencia ficción» literaria y, sobre todo, cinematográfica: Solaris, uno y dos (Mancino, 2012: 89-90 y 150). El propio Damiani cuenta que concibió su película como un acto respiratorio, de consciencia, hacia un enfoque determinístico, no importa si más o menos correcto, de hechos sorprendentes de la crónica políticojudicial italiana que confluyeron pocos años antes en Confessione di un commissario di polizia al procuratore della repubblica (1971). La razón subyacente induce a Damiani a volver sobre sus pasos, a ajustar las cuentas con los fantasmas de sus (excesivas) seguridades político-circunstanciales, compartidas por una opinión pública legítimamente indignada y, en parte, por una máquina judicial lenta, averiada, ambigua, lo cual revela a posteriori 
cómo el límite entre realidad e imaginación, verdad y mistificación, certeza y engaño, corre el peligro de desaparecer trágicamente en la Italia de la época. Y generar, si no remordimiento, una petición de falsificación necesaria, metodológicamente indispensable. $\mathrm{O}$ sea, un modo de reacción y de responsabilidad cinematográfica traducido en una trama capaz de rebatir la credibilidad oficial, insinuando, en lugar de la satisfacción con las formas de represalia y de justicia, una dosis significativa de inquietud, perplejidad y escepticismo:

Dos meses después de haber realizado yo Confessione di un commissario asesinaron a un magistrado [el controvertido fiscal Pietro Scaglione, el 5 de mayo de 1971, en Palermo]. Mi película no tenía nada que ver con ese caso, pero no pude hacer menos que sentir cierta perturbación frente a un hecho que, incluso sin una relación precisa con mi película, había venido para quedarse, si, naturalmente, aquel crimen no era un crimen privado, sino que tenía todas las motivaciones que constituían la columna vertebral dramática e ideológica de mi película. Fue aquel si, con toda la ambigüedad de sus posibles soluciones, el que me sugirió ¿Por qué se asesina a un magistrado? (apud Pezzotta, 2004: 263).

Con un fin provocativo o un propósito terapéutico, incluso frente a las pistas más fiables y manifiestas, Damiani se empeña entonces en contradecirse, sin eludir por ello la enormidad contextual de las Cosas italianas, que continúan siendo la contrapartida de la ciencia ficción o la deuda contraída con ella, de ahí el apellido, nomem omen, elegido en forma de presagio: Solaris. Un contrapunto que halla la máxima razón de ser en la fase particularmente aguda del crónico «déficit de verdad» nacional, principalmente en aquellos años setenta, por muchos motivos similares a un agujero negro o a un planeta que interactúa con la conciencia de cada uno de sus intrusos racionales, destrozándola. Años a los que, por otro lado, la expresión actual, aunque reductora de «años de plomo», ayuda a explicar al menos el recrudecimiento inaudito de la violencia terrorista, en continuidad, cuando no está esta en relación directa con el equilibrio criminal de la mafia siempre en activo. Después de todo, se trata, como siempre, de una Cosa (Nostra) $)^{3}$ inaprensible, siniestra e insidiosa. No sorprende, por lo tanto, percatarse en retrospectiva de cómo la «Cosa», con su marcada connotación y su legado inconfundible, obviamente en clave de ciencia ficción, había proporcionado la base para una interpretación excéntrica o paradójica de los acontecimientos, presentándose en ocasiones también como una contingencia efectiva. Sea como sea, metáfora, interpretación o contingencia, una «Cosa» indispensable para penetrar lo

\footnotetext{
${ }^{3}$ Por una curiosa coincidencia, también de fechas, la novela de Edward Wellen con el título de Hijack (Nueva York, Ballantine Books/Random House, 1970), se tituló en Italia Cosa Nostra che sei nei cieli (Milano, Mondadori, 1974).
} 


\section{¡Vigilad el cielo (y la tierra)!}

indecible en materia de atentados de origen mafioso y/o terrorista, entretejidos por oscuras tramas políticas.

Pero no acaba aquí la «Cosa». La «sincronicidad» y las redes de «coincidencias significativas» estimadas por Carl Gustav Jung (Synchronizität als ein Prinzip akausaler Zusammenhänge, 1952) y recibidas sobre un terreno muy tangible y detallado por el politólogo Giorgio Galle (Le coincidenze significative. Da Lovecraft a Jung, da Mussolini a Moro la sincronicità e la politica, 2010), crecen a nivel exponencial en aquellos años, en realidad tanto como en la recreación irónica provista por el medio cinematográfico, tanto de inmediato como a la distancia adecuada, también temporal. El indicio de estas «coincidencias», destinadas a cruzarse y a multiplicarse más allá de la medida del hombre, de la ciencia y del conocimiento, autorizando el recurso ya cotidiano y normal, ya paradójico y visionario de la «Cosa» como desencadenante de la ciencia ficción, es la difusión y el consumo de novelas y relatos de ciencia ficción que registra un aumento significativo en los años setenta, topándose con entusiastas o, asimismo, con simples admiradores, o tal vez sea más apropiado decir fisiológicamente entre los mismos brigadistas, como se evidencia en el caso Moro y, por ende, en Buenos días, noche (Buongiorno, notte, 2003), de Marco Bellocchio, que ya se había enfrentado emblemáticamente con la simulación delirante de la ciencia ficción en las secuencias de En el nombre del padre (Nel nome del padre, 1972), filme dispuesto a sugerir desde el título la función simbólica que Lacan ha llamado notoriamente «Nombre-del-padre». Elección más tarde confirmada a partir del trasunto de las películas que Bellocchio dedicó al fenómeno brigadista y al caso Moro, desde el último cartel de los créditos iniciales de El diablo en el cuerpo (Diavolo in corpo, 1986), que al nombre del director ejemplificado en la persona del analista antifreudiano Fagioli añade: «Dirección de Marco Bellocchio, quien dedica personalmente la película a Massimo Fagioli», y desde la dedicatoria «A mi padre» que inaugura Buenos días, noche. Y corresponde también a la ciencia ficción la indudable primacía de conceptualizar el estado insostenible de las Cosas que ocurren o actúan en un decenio «en los límites de la realidad», como demuestra Todo modo (1976), de Elio Petri, transposición cinematográfica muy libre y sugestiva de la novela homónima de Leonardo Sciascia, la cual empuja mucho el pedal moroteo. No por casualidad la referencia a la ciencia ficción se reserva, por derecho, al presidente «M[oro]», que lo expone al fiscal:

Doctor, yo debo presentar una hipótesis. Dura, dolorosa, amarga hipótesis, pero creíble teniendo en cuenta el momento que desde algunos años atrás está atravesando nuestra vida política y los lazos que la vinculan cada vez más tenazmente a la crónica de sucesos criminales, a la maldad, a la ciencia ficción, incluso. [...] A través de los muertos, alguien, no sé quién, que me oiga: no sé quién quiere hacernos llegar un mensaje, un aviso, una señal. [...] ¿Los hechos acaecidos en los últimos diez años en nuestro país no han tenido jamás, a su parecer, una explicación? 
La literatura de género y el cine italiano litigando con misterios, secretos $\mathrm{y}$ «pasos oscuros» de todo tipo dan vida, en el fondo, a un sistema de vasos comunicantes de realidad y ficción, Cose Nostre de diferente origen y procedencia. Extrañas, muy extrañas, y extrañantes. No menos que el objeto subespecie de la «Cosa» que conduce a Niccolò en Identificazione di una donna hasta su punto de observación/investigación favorito, la ventana, claro está. La escena en el guion transcrito encuentra su significado inequívoco en las palabras empleadas:

Mientras busca los cigarrillos que están sobre el alféizar de la ventana mira afuera. Algo llama su atención. Se levanta y sale a la terraza.

En la maraña de ramas de un pino tan alto como la casa hay una cosa [la cursiva es nuestra] que no había notado nunca antes: un objeto grisáceo sin forma. No está claro si está hecho de papel o de harapos, ni qué cosa [la cursiva es nuestra] es. Niccolò lo observa con curiosidad durante algunos instantes (Antonioni, 1983: 96).

Una «curiosidad» destinada a permanecer sin respuesta alguna la de Niccolò, que es la misma que la de Antonioni. O la de Bellocchio, quien permite a su vez a las ciencias ocultas y a la ciencia ficción retornar al tejido intermedio de Buenos días, noche, exactamente como se había dejado entrever en la crónica del caso Moro. Un discurso, este, que nos lleva automáticamente al delirio de la ciencia ficción de un verdadero loco, al servir en una institución religiosa anticuada (En el nombre del padre), dispuesto a exhibirse de nuevo en la pequeña pantalla (La macchina cinema, 1978). Merece la pena preguntarse cómo es posible que la ciencia ficción haya permanecido en silencio, indescriptible, mientras que el secuestro de Moro estaba en curso, cuando, desde un aparato de televisión permanentemente encendido en la guarida brigadista reconstruida en estudio por Bellocchio, llegan señales de este género literario particularmente en boga en Italia y en la política italiana durante la segunda mitad de los años setenta (Buenos días, noche). El crimen de Moro tiene mucho que ver con la ciencia ficción, además de con la ficción política — al menos con lo que parece ficción política pero no siempre lo es-, si acaso se piensa detenidamente. Pensemos en el piso-guarida brigadista de Vía Gradoli, descubierto la mañana del 18 de abril de 1978, el cual tiene algo de increíble. La guarida de Vía Gradoli es una de las «piezas que faltan» de Buenos días, noche. ¿Por qué no se ha mencionado jamás? Para mimetizar la perplejidad o eludir las trampas cognoscitivas. Lo cual no quiere decir, sin embargo, que se renuncie a la empresa de hacer entender su importancia. Vía Gradoli, al salir por la puerta principal de la película, vuelve a entrar por la ventana. Con la ciencia ficción colocada entre los pliegues de la complicada y, por lo que parece, incongruente historia del interior 11, escalera A, del segundo plano del número 96 de Vía Gradoli, el cual se convirtió desde 1974 en un auténtico lugar de paso, donde durante un cierto periodo vivieron Valerio Morucci y Adriana Faranda (Flamigni, 1999: 9, 14 


\section{¡Vigilad el cielo (y la tierra)!}

y 19), ya en el foco de interés de Antonioni y de su alter ego Niccolò (Identificazione de una donna), sin olvidar una hipótesis reciente: que dicho piso fuera una de las posibles prisiones por las que habría pasado Moro antes del 18 de abril (Limiti, 2009: 191-202) .

Ahora, si se tiene un poco de paciencia para proseguir con los casos italianos de terrorismo y de las Brigadas Rosas, vale la pena no perder de vista la «Cosa», es decir, el hilo «rojo» de la ciencia ficción, recordando que los inquilinos oficiales del piso en cuestión en abril de 1978 son, bajo un nombre falso, los dos brigadistas Mario Moretti y su compañera Barbara Balzerani. Y es que aquel 18 de abril encontramos en este bazar brigadista, «imponente "escaparate" de pruebas» (Martinelli y Padellaro, 1979: 122123), que contiene más de mil hallazgos de todo tipo, objetos menos necesarios, sí, pero no por ello insignificantes, si nos vemos atrapados en esa perspectiva de ciencia ficción en la que no es momento aquí de insistir, sino con el propio Bellochio, desde En el nombre del padre a Buenos días, noche. Se trata, pues, de los libros, de la completa biblioteca «polimorfa», de hecho, que comprende «novelas de ciencia ficción desde Asimov hasta colecciones enteras de Urania»: si bien de escaso valor probatorio, para Vicenzo Caretti, un psicólogo junguiano, «una relación entre la estructura simbólica de la novela de ciencia ficción y la utopía política de las Brigadas Rojas» (Martinelli y Padellaro, 1979: 128). De este tipo de lecturas se habla, asimismo, en la (casi) autobiografía de la Faranda:

Todo fue recolectado y confiscado, incluido el material utilizado por Moretti para falsificar la documentación de los autos robados y decenas de libros de ciencia ficción, un género por el cual el jefe de las BR tenía una verdadera pasión. Una predilección que «Maurizio» compartía con Adriana que, al mudarse a Vía Chiabrera, había dejado en la antigua dirección una discreta colección de Urania y todos sus volúmenes de Isaac Asimov, de quien ambos eran grandes admiradores (Mazzocchi, 1994: 114).

Es preciso tener presente que Bellocchio tenía en proyecto realizar una película sobre/de la Faranda, proyecto al cual, en 1995, después de Sogni infranti. Ragionamenti e deliri (1995), renuncia por diferencias con la exbrigadista $^{5}$. Basándose en esa clase especial de material encontrado en la guarida de Vía Gradoli, el libro subraya la «verdadera pasión» y la «afición» por la ciencia ficción compartida por la Faranda y Moretti. Como hace enseguida también la brigadista Anna Laura Braghetti en el libro igualmente autobiográfico del que Bellocchio toma oficialmente Buenos días, noche: «Luego me detuve en el puesto de periódicos y compré algunas novelas de

\footnotetext{
${ }^{4}$ Véase también el documental Sequestro Moro. Sentenza di morte (2011), dirigido por Franco Fracassi y escrito por el periodista Lorenzo Fiorillo, Giulia Migneco y Carla Sollazzo.

${ }^{5}$ Véase «Film sulle BR, lite Bellocchio Faranda» (Corriere della Sera, 09/11/1995) y Malanga (1998: 233).
} 
ciencia ficción de la serie Urania, el género favorito de muchos militantes de las Brigadas Rojas» (Braghetti y Tavella, 2008: 27). A Bellocchio esta circunstancia no le interesa. Prefiere más bien la atmósfera mucho más «propia de la ciencia ficción» que lo envuelve todo, remontándose a los delirios utópicos del loco Tino de En el nombre del padre, que habla «en la lengua de los habitantes de Mongo», atmósfera inspirada por el género literario «predilecto» de esos dos o de más brigadistas; por consiguiente, por los libros encontrados, entre tantísimas otras cosas, en la vía eliminada del filme. Incluso en la parte posterior de la portada de un libro de ciencia ficción de la colección de la guarida de Vía Gradoli se ha observado, probablemente por Moretti, el nombre de una marquesa y el de un tranquilizante, esto es, uno de los medicamentos necesarios para el prisionero, así como un número de teléfono y una fecha que rastrean investigadores y estudiosos, principalmente los conspiranoicos, llevándolos hasta un edificio nobiliario en las proximidades de Vía Caetani y una sociedad inmobiliaria (Flamigni, 2003: 354-355; Flamigni, 1999: 117-121), confirmando la pista de la investigación que conduce al barrio judío. Limitémonos a tener muy presente cómo en aquellos años se continúa registrando una recuperación, en cierto sentido sintomática, de la ciencia ficción:

Sobre la existencia o no de un auténtico boom de la ciencia ficción en Italia podría discutirse, pero la proliferación de libros (novedades y reimpresiones), nuevas colecciones, editoriales no especializadas que se abren a este sector es un hecho más que evidente que no necesita confirmación (Spagnul, 1979: 245).

Y nótese cómo en Buenos días, noche la ciencia ficción no se llega a borrar del todo, tampoco hay pasos que no dejan huella. Quizá no se ve bastante, pero se siente. Después de la escena del descubrimiento en el ascensor de la estrella de cinco puntas que ha hecho cundir el pánico entre muchos empleados ministeriales, Chiara vuelve al apartamento y halla a sus compañeros muy ocupados, mientras que desde el fondo llega del televisor una voz que solo es audible a trozos, dado el bajo volumen:

Aquí, antes de hablar sobre la primera película, una declaración: como saben, como todos sabemos, este es el mejor de los mundos posibles. [...] Es este el motivo por el que, tal vez, se ha difundido esta moda, podríamos decir, $[\ldots]$ de la ciencia ficción, de encuentros en la tercera fase, [...] de literatura de ciencia ficción... la voluntad, en suma, de evadirnos de un mundo, aunque sea el mejor de los mundos posibles; sin embargo... alguna vez entran ganas de escapar un poquito. La película que veremos es una especie de testimonio sobre los ovnis...

Son muchas también las formas típicas de la ciencia ficción, o ficción política, que Bellocchio recorre para construir desde hace muchos años las tramas de sus películas. No es, en todos los sentidos, «Cosa» de poco valor. 


\section{¡Vigilad el cielo (y la tierra)!}

Ya no existe solo la utopía distorsionada o la distopía para alimentar el ideal bastante indeseable de regeneración social de Angelo y Tino al final de En el nombre del padre. Por ejemplo, en Buenos días, noche, Il regista di matrimoni y Vincere con frecuencia nos topamos con casos típicos de fragmentos, episodios temporales, escenas individuales que están separadas del curso lineal de los sucesos o que se salen de la posición asignada por la cronología oficial. Para permanecer en el entorno de la ciencia ficción/ficción política, con una más marcada connotación psíquica, se podría, en resumen, hablar de discronía (Chiodi, 2011: 161), modalidad temporal «herética» que caracteriza por ejemplo el final desdoblado y muy debatido de Buenos días, noche, donde asistimos a las imágenes de archivo del funeral del Moro real, al tiempo que, paralelamente, el Moro de Bellocchio pasea imperturbable por una calle de Roma. O el final inmediatamente posterior de Il regista di matrimoni (2006), en el que nuevamente el curso más o menos lineal de los acontecimientos y de las posibilidades narrativas se bifurca. $\mathrm{O}$ aun el episodio de Vincere (2009), que inaugura y concluye la parábola ascendente/descendente de Mussolini, provocando incluso a Dios. Un Dios extremamente severo, el cual, se entiende al final, parece haber aceptado de veras el reto «teológico» del joven Mussolini, destruyéndolo en aquel «lapso» de tiempo que puede durar pocos segundos y haber durado algunos decenios, no marca la diferencia:

SACERDOTE: Por favor, por favor, señores, un poco de silencio. En este escenario, en esta singular lucha de carácter teológico, después de la docta exposición de don Moretti cedo la palabra al señor Benito Mussolini, sindicalista, así como exponente del Partido socialista. A pesar de las opiniones opuestas, distintas, creo que es justo oír su exposición y que pueda expresarse libremente. Por favor.

MUSSOLINI: Seré muy breve. ¿Alguno de ustedes tiene un reloj? (Un señor en primera fila se lo da). No se preocupe, no soy un ladrón. Son las cinco y diez. ¡Yo desafío a Dios! (Voces de desconcierto entre los asistentes). Le doy de tiempo cinco minutos para fulminarme. Si no me fulmina, será la demostración de que no existe. Estoy preparado. (Se queda inmóvil, a la espera, en el silencio general). El tiempo expiró: ¡Dios no existe!

Como es sabido, la última escena de Vincere nos lleva a la situación inicial. Los cinco minutos, reloj en mano, puede ser que no hayan expirado aún. Porque el Duce ya ha acabado. Los noticiarios de la época muestran en rápida sucesión la abominable declaración de guerra, los bombardeos, la caída del régimen. Y su busto monumental aplastado por una prensa. La suerte de Mussolini está inscrita en la brevísima/larguísima espera de la escena de apertura y cierre o, paralelamente, en todo el arco temporal y narrativo del filme. Cualquiera que sea la opción temporal, el destino no cambia. Como no cambia el nombre del padre en la «singular lucha de carácter teológico» que con su «docta exposición» ha precedido la intervención autodestructiva de Mussolini: se llama casualmente «don Moretti», como el otro Moretti, el jefe brigadista que vivió en el piso de Vía 
Gradoli 96 hasta la mañana del 18 de abril de 1978. Y que en Buenos días, noche se llama Mariano.

Sean estos de ciencia ficción, de ficción política o de cualquier otro género, los libros que hallamos en el caso, del caso y sobre el caso Moro hacen el «caso/Cosa» Moro. La «babélica» moroteca que ha ido creciendo y consolidándose durante decenios, irreversiblemente, como el alienígena igualmente «polimórfico». Bastante inadvertida, pero a la vista hermosa $\mathrm{y}$ cruel en la película de Carpenter, proporciona la prueba irrefutable de la (des)medida de un Caso a estas alturas paralelamente tentacular, al cual se unen infinitos otros casos, «Cosas», a menudo y de buena gana, interceptadas por el cine, a las que, además, ya no se puede detener al avanzar a lo largo de una trayectoria continua, lineal y cronológica, o al prescindir de las pistas, verosímiles e inverosímiles, creíbles e increíbles, lógicas y conspiranoicas, concretas y místicas, realistas y propias de la ciencia ficción, las cuales confirman y potencian cada vez, con Antonioni, Bellocchio, Damiani, Moretti, Petri, el impecable recurso de la «Cosa» como instrumento de conocimiento transversal.

\section{Bibliografía CITADA}

ANTONIONI, Michelangelo (1983), Identificazione de una donna, ed. de Aldo Tassone, Torino, Einaudi.

Arona, Danilo (1983), «La forma della cosa», Cinema \& Cinema, 34, págs. 37-40.

Braghetti, Anna Laura y Paola Tavella (2008), Il prigioniero, Milano, Feltrinelli.

Campbell, John W., (1955), Who Goes There? and other stories. New York, Dell Books.

Chiodi, Giulio Maria (2011), La coscienza liminare. Sui fondamenti della simbologia politica, Roma, Franco Angeli.

Flamigni, Sergio (1999), Il covo di Stato. Via Gradoli 96 e il delitto Moro, Milano, Kaos.

Flamigni, Sergio (2003), La tela del ragno, Milano, Kaos.

LACAN, Jacques (2008), «Introduzione della Cosa», en Il seminario. Libro VII. L'etica della psicoanalisi. 1959-1960, Torino, Einaudi.

LEM, Stanislaw (1988), Solaris, Barcelona, Minotauro.

Limiti, Stefania (2009), L'Anello della Repubblica, Milano, Chiarelettere.

Malanga, Paola [ed.] (1998), Marco Bellocchio. Catalogo Ragionato, Milano, Olivares.

Mancino, Anton Giulio (2012), Schermi d'inchiesta. Gli autori del film politico-indiziario italiano, Torino, Kaplan.

Martinelli, Roberto y Antonio Padellaro (1979), Il delitto Moro, Milano, Rizzoli.

Mazzochi, Silvana (1994), Nell'anno della tigre. Storia di Adriana Faranda, Milano, Baldini \& Castoldi. 
¡Vigilad el cielo (y la tierra)!

Pezzotta, Alberto (2004), Regia Damiano Damiani, Pordenone, Cinemazero.

SpAgnul, Giuliano (1979), «La critica», en AA.VV. (Collettivo Un ambigua utopia), Nei labirinti della fantascienza. Guida critica, Milano, Feltrinelli.

ŽıžEK, Slavoj (2011), Tarkovskij: la cosa dallo spazio profondo, Milano, Mimesis.

Fecha de recepción: 07/04/2020.

Fecha de aceptación: 25/07/2020. 